\title{
Ictiofauna dos córregos do Parque Nacional de Brasília, bacia do Alto Rio Paraná, Distrito Federal, Brasil Central
}

\author{
Pedro De Podestà Uchôa de Aquino ${ }^{1,3,4}$, Mariana Schneider ${ }^{1,3}$, Maria Júlia Martins Silva ${ }^{1}$, \\ Claudia Padovesi Fonseca ${ }^{2,3}$, Henrique Breda Arakawa ${ }^{1}$ \& Douglas Rodrigues Cavalcanti ${ }^{1}$ \\ ${ }^{1}$ Laboratório de Bentos, Departamento de Zoologia, http://www.unb.br/ib/zoo/ \\ ${ }^{2}$ Departamento de Ecologia, Instituto de Ciências Biológicas, \\ Campus Darcy Ribeiro, Universidade de Brasília - UnB, \\ ICC norte, Asa Norte, Brasília, Brasil, http://www.unb.br/ib/ecl/, http://www.unb.br/ib/ \\ ${ }^{3}$ Programa de Pós-Graduação em Ecologia, Campus Darcy Ribeiro, Universidade de Brasília - UnB, \\ ICC norte, Asa Norte, Brasília, Brasil, http://www.unb.br/ib/ecl/posecl/ \\ ${ }^{4}$ Autor para correspondência: Pedro De Podestà Uchôa de Aquino, e-mail: pedropua@gmail.com
}

AQUINO, P.P.U., SCHNEIDER, M., MARTINS-SILVA, M.J., PADOVESI-FONSECA, C., ARAKAWA, H.B. \& CAVALCANTI, D.R. 2009. The fishfauna of Parque Nacional de Brasília, upper Paraná River basin, Federal District, Central Brazil. Biota Neotrop. 9(1): http://www.biotaneotropica.org.br/v9n1/en/abstract?in ventory+bn02809012009.

Abstract: The aims of this study were to survey the stream fishes of Parque Nacional de Brasília, Federal District, and identify its community structure variation. We sampled streams in the Bananal and Santa Maria/Torto subbasins at Upper Paraná River. Lotic systems in this region are well preserved, as indicated by environmental integrity and the maintenance of native biological components. A total of 8,614 individuals were collected belonging to four orders, nine families, and twenty-eight species (being 11 new to science). The predominant order was Characiformes, followed by Siluriformes. Poecilia reticulata was the only nonnative fish specie found. Astyanax sp. and Hyphessobrycon balbus displayed widest spatial distribution. The most abundant species was Knodus moenkhausii with $64.5 \%$ of individuals. Highest fish richness and abundance were found in the wider and deeper stretches.

Keywords: headwaters, fish diversity, endemism, Cerrado conservation.

AQUINO, P.P.U., SCHNEIDER, M., MARTINS-SILVA, M.J., PADOVESI-FONSECA, C., ARAKAWA, H.B. \& CAVALCANTI, D.R. 2009. Ictiofauna dos córregos do Parque Nacional de Brasília, bacia do Alto Rio Paraná, Distrito Federal, Brasil Central. Biota Neotrop. 9(1): http://www.biotaneotropica.org.br/v9n1/pt/abs tract?inventory+bn02809012009.

Resumo: O objetivo do presente estudo foi realizar o inventário da fauna íctica dos córregos do Parque Nacional de Brasília no Distrito Federal e caracterizar a estrutura da comunidade íctica ao longo dos cursos d'água. Foram amostrados córregos das sub-bacias do Bananal e Santa Maria/Torto na região hidrográfica do Alto Rio Paraná. Esses cursos d'água apresentam bom estado de preservação, evidenciado na integridade de suas características ambientais naturais e na manutenção dos componentes biológicos nativos. Um total de 8.614 indivíduos, distribuídos em quatro ordens e nove famílias, foram coletados. A ordem com maior número de espécies foi a Characiformes, seguida por Siluriformes. Das 28 espécies encontradas 11 são novas para a ciência. Apenas a espécie exótica Poecilia reticulata foi encontrada. Astyanax sp. e Hyphessobrycon balbus foram as espécies com maior distribuição na área de estudo e Knodus moenkhausii apresentou a maior abundância (64,5\% dos indivíduos). Nos trechos com maiores larguras e profundidades foram encontrados maiores valores de riqueza de espécies e abundância de indivíduos.

Palavras-chave: cabeceiras, diversidade íctica, endemismo, conservação do Cerrado. 


\section{Introdução}

A fauna íctica de água doce da América do Sul possui uma grande diversidade e complexidade; no entanto, o conhecimento da ecologia, biologia e sistemática desse grupo, apesar de crescente, mostra-se ainda incompleto (Vari \& Malabarba 1998). A bacia do Alto Rio Paraná encontra-se totalmente em terras brasileiras, atravessando os estados de Goiás, Mato Grosso do Sul, São Paulo, Paraná e o Distrito Federal. Corresponde ao primeiro terço da bacia do Rio Paraná, ocupando uma área de $891.000 \mathrm{~km}^{2}$ (10,5\% do território brasileiro) (Agostinho et al. 2004). Essa bacia possui um grande número de espécies de peixes ( 310 descritas e 60 em diferentes fases de descrição) com expectativa de descoberta de novos táxons, frente ao crescimento de estudos em regiões pouco exploradas (e.g., regiões de cabeceira, lagoas marginais de rios e represas) (Langeani et al. 2007). No entanto, sua integridade tem sido fortemente afetada pela crescente ação antrópica. Entre os principais fatores que prejudicam a conservação da biodiversidade em águas continentais brasileiras, destacam-se os barramentos, a percolação de pesticidas e fertilizantes utilizados em plantações, as drenagens, a retirada da vegetação ripária, a emissão de efluentes, a pesca predatória e a introdução de espécies exóticas (Agostinho et al. 2005).

Recentes inventários em riachos da bacia do Alto Rio Paraná, principalmente na região Sudeste do Brasil, evidenciam a grande diversidade da bacia e revelam a especificidade desses ambientes frente à constante descoberta de novas espécies (Casatti et al. 2001, Castro et al. 2003, 2004, 2005, Langeani et al. 2005, Apone et al. 2008). Apesar de crescentes, ainda são encontrados poucos estudos sistematizados envolvendo a taxocenose íctica em riachos dessa bacia na região Centro-Oeste. Entre esses estudos, Benedito-Cecilio et al. (2004) estudando a ictiofauna do Parque Nacional das Emas, identificaram sete espécies de peixes para os córregos pertencentes a bacia do Alto Rio Paraná. Araújo \& Tejerina-Garro (2007) e Fialho et al. (2007) também realizaram estudos ictiofaunísticos nessa bacia, no estado de Goiás, e identificaram 35 e 59 espécies, respectivamente. No Distrito Federal, avaliando a estrutura da comunidade de peixes do Ribeirão Santana, Viana (1989) identificou 40 espécies e verificou que com o aumento da complexidade do ambiente, ao longo do gradiente ambiental, maior foi a diversidade de peixes. Em pesquisa realizada nos córregos da Estação Ecológica de Águas Emendadas, também no Distrito Federal, Ribeiro et al. (2008) identificaram 41 espécies de peixes para a unidade hidrográfica do Rio Paraná. Esses pesquisadores ressaltam, ainda, a importância biogeográfica desses mananciais hídricos e apontam o forte endemismo encontrado na região.

As regiões de cabeceira das unidades hidrográficas são caracterizadas por possuírem menores diversidades de hábitats (volume e complexidade) e pouca estabilidade das variáveis ambientais (Schlosser 1990, Jackson et al. 2001). Esses córregos apresentam pequeno volume de água e cursos irregulares. As espécies de peixes que ocorrem nessas regiões são de pequeno porte, curto período de vida e precoce maturação sexual (Schlosser 1990). O tamanho reduzido desses indivíduos impede a realização de grandes deslocamentos tornando as populações isoladas, favorecendo processos de especiação e endemismos (Castro 1999). A distribuição dessas espécies em riachos apresenta-se direcionada, principalmente, por variações hidrogeológicas (i.e., forte interação espécie-hábitat) (Gorman \& Karr 1978, Poff 1997) e em menor proporção por interações biológicas (Peres-Neto 2004). A manutenção das características naturais desses ambientes é imprescindível devido à grande dependência das espécies por esses peculiares ecossistemas. A integridade das Matas de Galeria, por exemplo, mostra-se necessária, uma vez que muitas espécies de peixes usam-nas para alimentação, reprodução e abrigo (Lowe-McConnell 1999).
Estudos em regiões que preservam características naturais e que sofreram pouca interferência humana são importantes referências para políticas públicas conservacionistas. A composição da comunidade e o entendimento dos padrões de distribuição das espécies de peixes mostram-se bastante úteis na avaliação da integridade dos ecossistemas aquáticos (e.g., Karr 1981). Compreender como as comunidades biológicas se distribuem no ambiente natural viabiliza ações de gestão e manejo que minimizam a degradação desses ecossistemas (Schlosser 1990). Frente ao apresentado, o objetivo do presente estudo foi realizar o inventário da ictiofauna dos córregos do Parque Nacional de Brasília, que pertencem à bacia do Alto Rio Paraná, bem como caracterizar a estrutura da comunidade íctica ao longo dos cursos d'água. Essas informações poderão ser utilizadas como referência para riachos preservados de cabeceira as quais poderão subsidiar futuros estudos de biomonitoramentos e recuperação de áreas degradadas.

\section{Material e Métodos}

\section{Local de estudo}

O estudo foi realizado no Parque Nacional de Brasília (PNB), maior Unidade de Conservação de Proteção Integral do Distrito Federal, com 42.389 ha, área correspondente a 7,31\% do Distrito Federal (MMA \& TNC 2007). Pela sua posição no Brasil Central, apresenta clima tropical caracterizado por elevadas temperaturas (média anual de $21{ }^{\circ} \mathrm{C}$ ) e duas estações bem definidas: estação seca e fria durante o inverno e estação chuvosa e quente durante o verão. A precipitação média anual chega a $1.600 \mathrm{~mm}$, com chuvas concentradas nos meses de dezembro e janeiro e quase inexistentes em julho e agosto. Apresenta vegetação predominante de Cerrado, em sua maior parte Cerrado sensu stricto.

Neste estudo foram amostrados cursos d'água pertencentes às sub-bacias dos Ribeirões do Bananal e Santa Maria/Torto, os quais deságuam no Lago Paranoá que faz parte da Bacia do Rio São Bartolomeu. Essa região localiza-se ao norte da bacia do Alto Rio Paraná sendo separada da bacia do Tocantins/Araguaia pela Chapada da Contagem (Pinto 1993).

Com o acelerado crescimento urbano no Distrito Federal, grandes parcelas de Cerrado vêm sendo perdidas (UNESCO 2001). Neste contexto, o Parque Nacional de Brasília torna-se cada vez mais insularizado, o que compromete sua zona de amortecimento prevista em termos legais pelo Sistema Nacional de Unidades de Conservação da Natureza (SNUC, Lei 9.985, de 18 de julho de 2000). A represa de Santa Maria, formada pelo barramento dos córregos Santa Maria, Milho Cozido e Vargem Grande, possui águas dentro dos padrões de potabilidade e abastece parte do Distrito Federal. Muitas amostras representativas do bioma Cerrado encontram-se preservadas pela manutenção dessa Unidade de Conservação. Sua importância é, ainda, evidenciada nas atividades de educação ambiental e incentivo às pesquisas científicas, contribuindo para maior conhecimento do bioma Cerrado (IBAMA \& FUNATURA 1998).

\section{Desenho amostral}

Nas sub-bacias do Bananal e Santa Maria/Torto foram selecionadas 14 unidades amostrais, sete em cada sub-bacia (Tabela $1 \mathrm{e}$ Figuras 1 e 2). As informações quanto à ordem dos trechos amostrados (Horton 1945, Strahler 1957) foram extraídas do mapa dos reservatórios das águas de superfície e subterrâneas do Parque Nacional de Brasília, na escala 1:50.000 (IBAMA \& FUNATURA 1998). O ponto médio de cada unidade amostral foi georreferenciada (latitude, longitude e altitude) via satélite com um GPS (GPS Garmin Etrex Venture ${ }^{\circledR}$ ). Ao longo dos cursos d'água é possível observar preservadas 
Ictiofauna dos córregos do Parque Nacional de Brasília

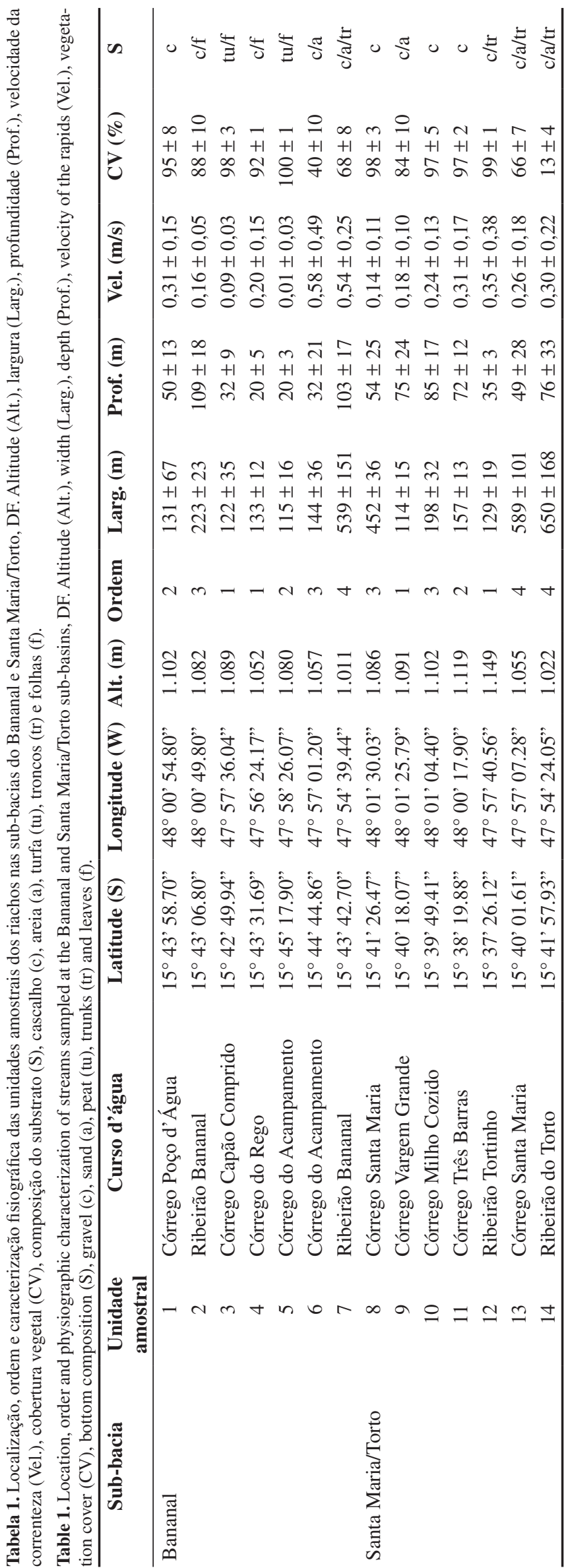




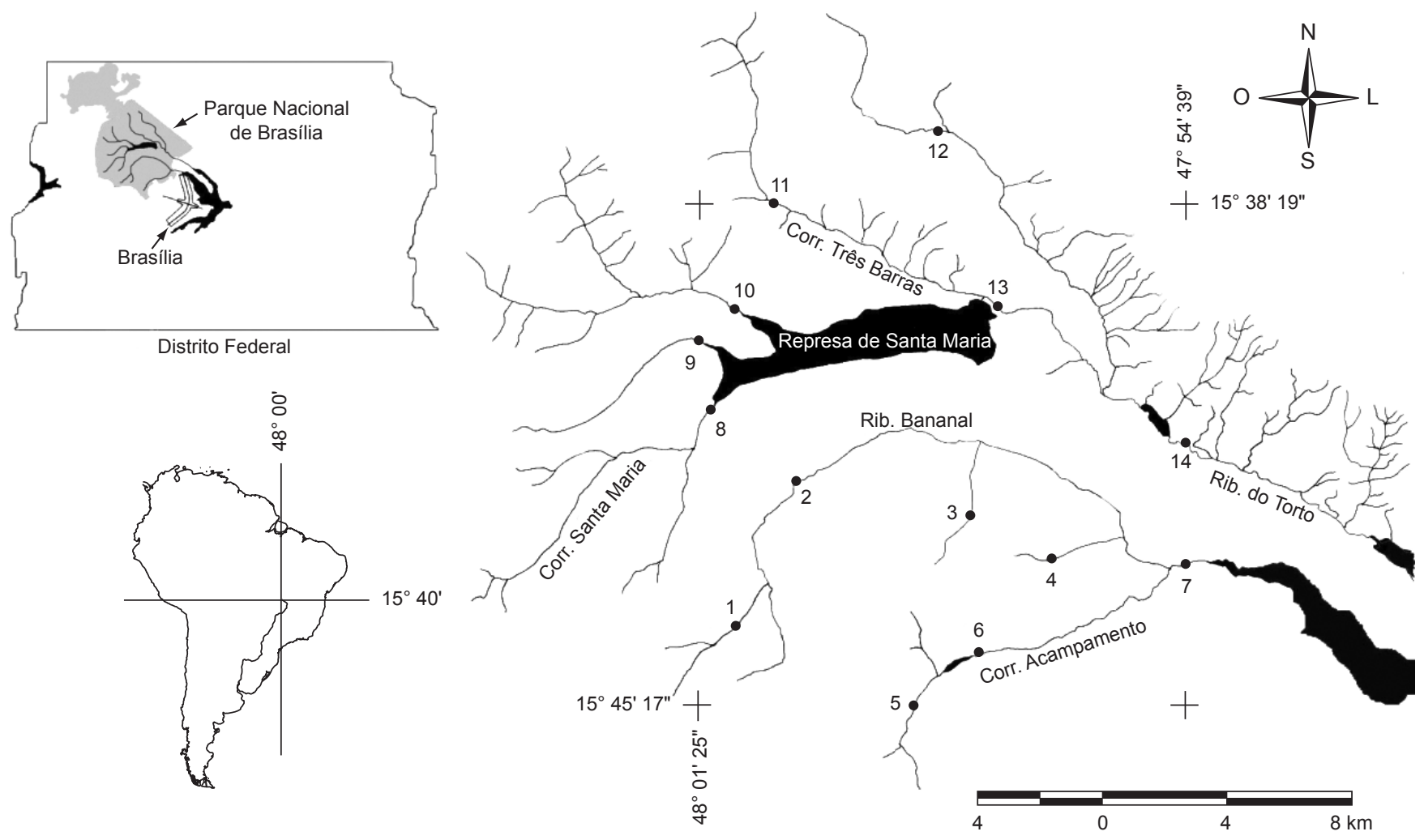

Figura 1. Trechos amostrados nos córregos das sub-bacias do Bananal (1 a 7) e Santa Maria/Torto (8 a 14), DF.

Figure 1. Stretches sampled at the Bananal (1 to 7) and Santa Maria/Torto (8 to 14) sub-basins, DF.

Matas de Galeria (trechos 1 a 5 e 8 a 12) e Matas Ciliares (trechos 6, 7, 13 e 14) (Figura 1).

Foram realizadas quatro excursões de coleta: transição do período de seca para o período chuvoso ( 28 de setembro a 9 de outubro de 2006), período chuvoso (8 a 12 de janeiro de 2007), transição do período de chuva para o período de seca (18 a 26 de abril de 2007) e período de seca ( 9 a 13 de julho de 2007). Em cada unidade amostral foram medidas, ao longo do ano, as larguras e as profundidades com uma trena, a velocidade da correnteza com um medidor de fluxo líquido (FLOWATCH ${ }^{\circledR}$ ) e a cobertura vegetal com um densiômetro florestal esférico (Tabela 1). A composição do substrato foi também caracterizada quanto à presença predominante de cascalho, areia, turfa, troncos e folhas (Tabela 1).

As coletas dos peixes foram realizadas durante o período diurno, com a combinação de diversos métodos de captura, buscando amostrar a totalidade da ictiofauna presente em cada unidade amostral. As coletas foram realizadas percorrendo-se um trecho padronizado de $30 \mathrm{~m}$ de extensão, com a utilização de peneiras $(30 \mathrm{~cm}$ de raio e malha $2 \mathrm{~mm}$ ) e redes de arrasto ( $3 \times 1 \mathrm{~m}$ e malha $2 \mathrm{~mm})$, até que o número de exemplares tendesse a zero. Os trechos foram percorridos de jusante a montante (contra o fluxo da água) para evitar o levantamento de suspensão que poderia afugentar os peixes. Em trechos que apresentaram maiores profundidades, foram utilizadas redes de emalhar ( $10 \times 1,5 \mathrm{~m}$ e $2 \mathrm{~cm}$ entre nós), que permaneceram montadas enquanto as demais metodologias de coletas eram realizadas.

Os exemplares foram fixados em formol a $10 \%$ e, posteriormente, conservados em etanol a 70\% (Uieda \& Castro 1999). A identificação foi realizada com o uso de chaves de identificação (Castro et al. 2003, 2004) e auxílio de especialistas para cada grupo específico. O material testemunho foi depositado na Coleção Ictiológica da Universidade de Brasília (CIUnB) e na Coleção de Peixes do Departamento de Zoologia e Botânica da Universidade Estadual Paulista, São José do Rio Preto (DZSJRP) (Anexo).

\section{Análise dos dados}

A curva de acumulação de espécies, expressa pelo número de indivíduos coletados foi gerada a fim de avaliar a adequação da metodologia de coleta dos peixes (Gotelli \& Colwell 2001). A curva foi gerada a partir de 1.000 permutações aleatórias utilizando o comando "specaccum" do pacote "vegan" (Oksanen et al. 2007) no programa estatístico R (R Development Core Team 2007). Para avaliar a eficiência do inventário, foram utilizados os estimadores da riqueza por extrapolação Chao1 (Chao 1987) e ACE (Abundance-based Coverage Estimator, Lee \& Chao 1994), que levam em consideração as espécies raras e heterogeneidades nas coletas. Para esta análise, utilizou-se o comando "estimateR" do pacote "vegan" no mesmo programa estatístico.

Para verificar a constância de ocorrência das espécies, foi utilizada a fórmula de Dajoz (1978), onde são obtidas algumas informações quanto à distribuição das espécies: $\mathrm{C}=(\mathrm{p} / \mathrm{P})$ x 100 (C é o valor de constância da espécie, $\mathrm{p}$ é o número de coletas contendo a espécie estudada e $\mathrm{P}$ é o número total de coletas efetuadas). Uma espécie é considerada constante quando apresenta $\mathrm{C}>50 \%$, acessória quando $50 \% \geq \mathrm{C} \geq 25 \%$ e acidental $\mathrm{C}<25 \%$.

O número total de espécies $(\mathrm{S})$, o número total de indivíduos $(\mathrm{N})$ e o índice de $\operatorname{Simpson}\left(l=1-\sum \mathrm{p}_{\mathrm{i}}{ }^{2}\right.$, onde $\mathrm{p}_{\mathrm{i}}$ é a abundância relativa da 
Ictiofauna dos córregos do Parque Nacional de Brasília
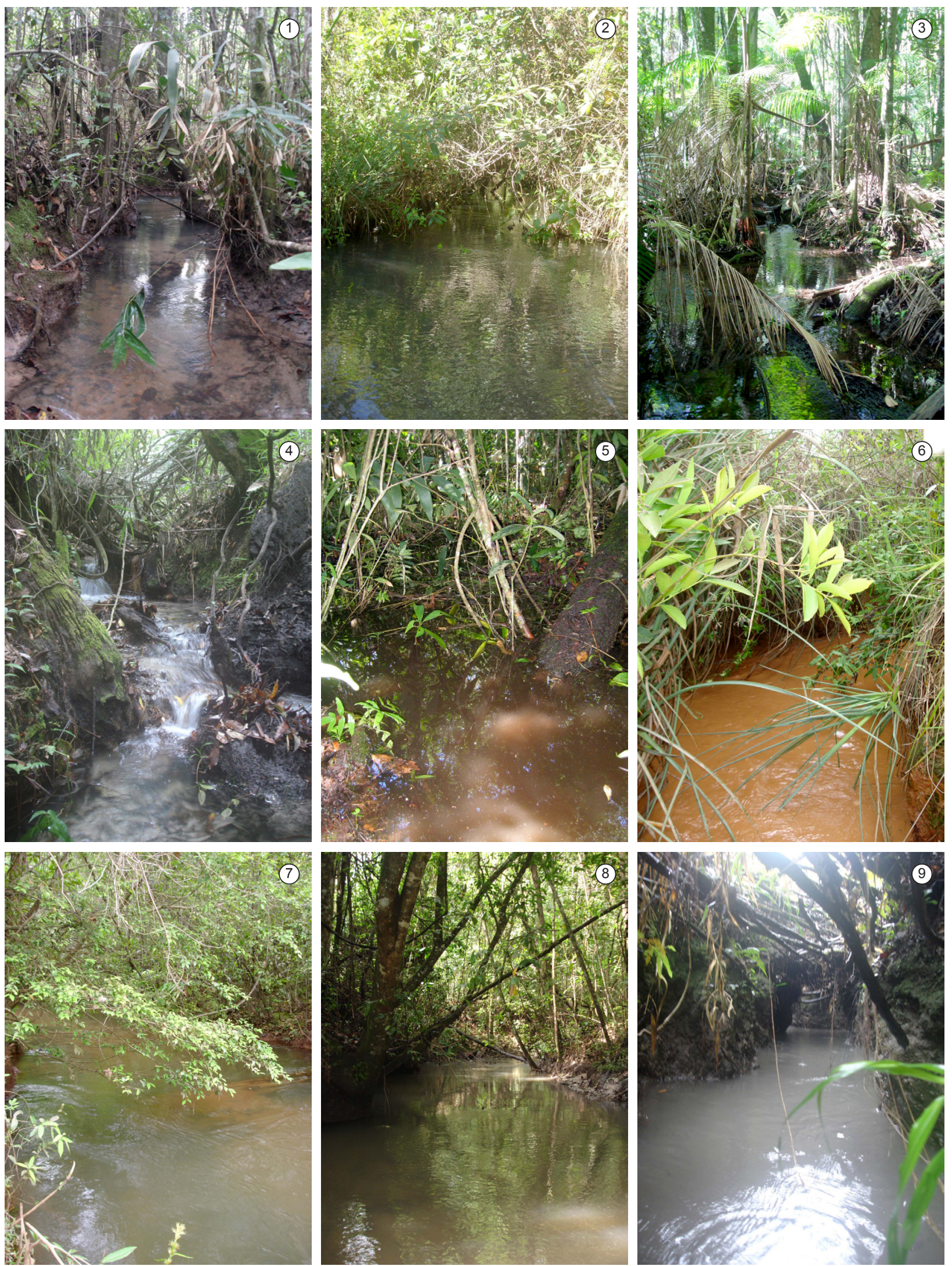

Figura 2. Vista geral das unidades amostrais: de 1 a 7 unidades pertencentes à sub-bacia Bananal e de 8 a 14, à sub-bacia Santa Maria/Torto, DF (Fotos de Pedro De Podestà e Mariana Schneider).

Figure 2. Overview of sampled stretches: Bananal sub-basin (1-7) and Santa Maria/Torto sub-basin (8-14), DF (Pictures by Pedro De Podestà and Mariana Schneider). 

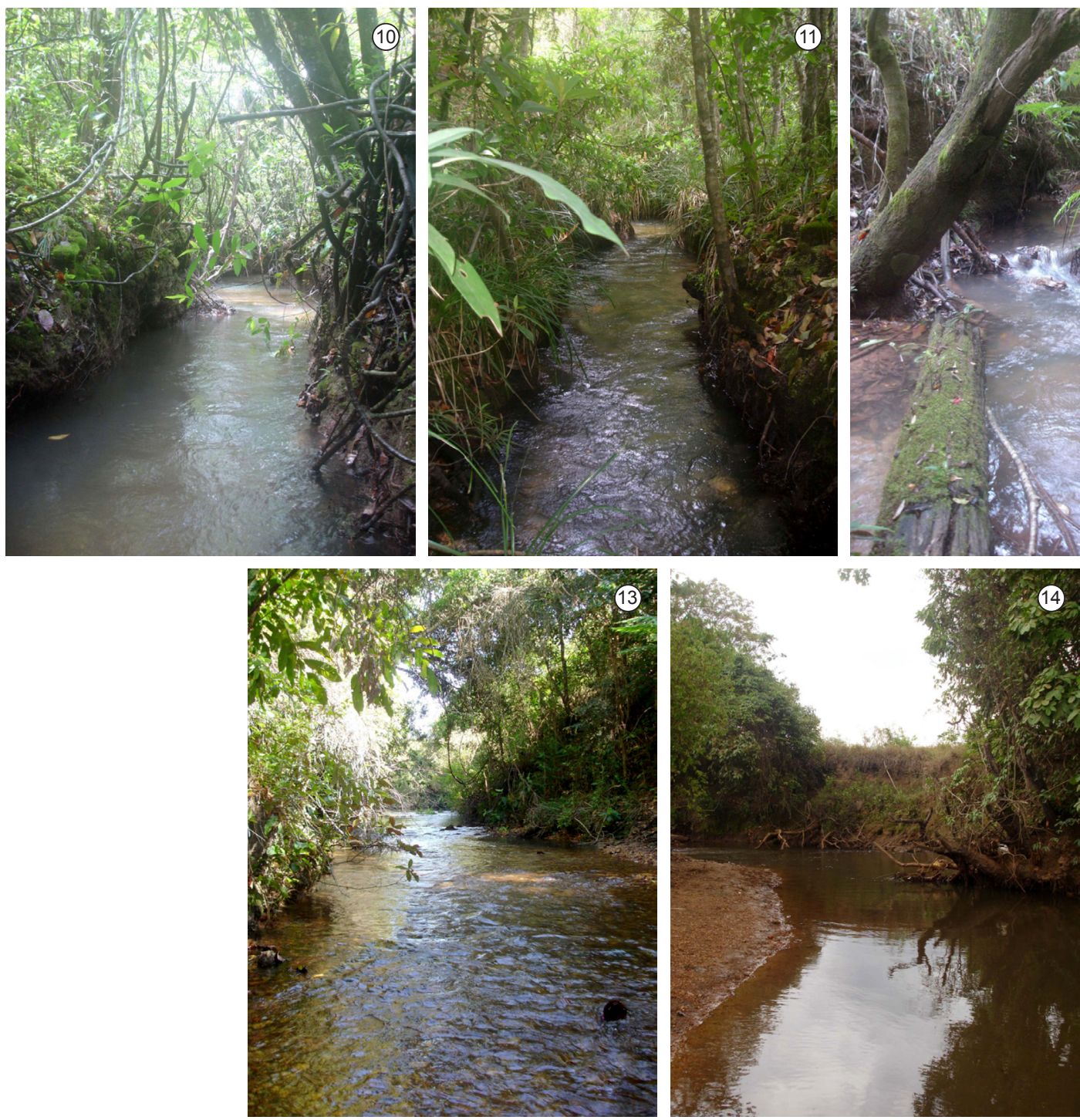

Figura 2 (Continuação). Vista geral das unidades amostrais: de 1 a 7 unidades pertencentes à sub-bacia Bananal e de 8 a 14, à sub-bacia Santa Maria/Torto, DF (Fotos de Pedro De Podestà e Mariana Schneider).

Figure 2 (Continued). Overview of sampled stretches: Bananal sub-basin (1-7) and Santa Maria/Torto sub-basin (8-14), DF (Pictures by Pedro De Podestà and Mariana Schneider).

espécie i) foram calculados para cada amostragem (Magurran 1988, Mouillot \& Leprêtre 1999).

\section{Resultados}

A curva de acumulação do número de espécies em função do número de indivíduos coletados, gerada a partir de permutações aleatórias dos indivíduos, é apresentada na Figura 3. O estimador de riqueza Chaol apresentou uma estimativa de $29 \pm 3$ e ACE de $30 \pm 3$ espécies de peixes para os riachos amostrados.

Foram coletados 8.614 indivíduos distribuídos em quatro ordens, nove famílias, 21 gêneros e 28 espécies (Tabela 2 e Figuras 4, 5 e 6). Das espécies coletadas, 50,0\% pertencem à ordem Characiformes, $35,7 \%$ à Siluriformes, $10,7 \%$ à Cyprinodontiformes e 3,6\% à Perciformes. A ordem com o maior número de indivíduos foi a Characiformes, com 8.388 exemplares $(97,4 \%)$. A família com maior número de espécies foi Characidae (32,1\%), seguida por Loricariidae $(25,0 \%)$. As espécies mais abundantes foram Knodus moenkhausii

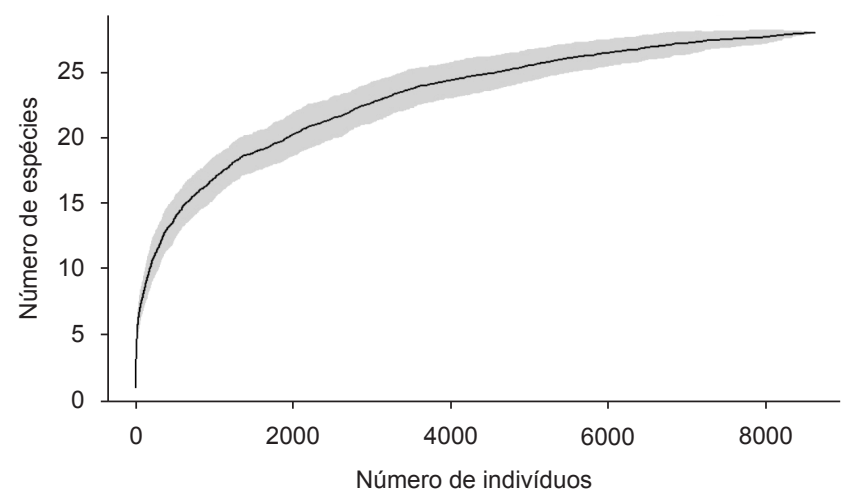

Figura 3. Curva de acumulação de espécies gerada a partir de permutações aleatórias dos indivíduos coletados nos córregos das sub-bacias do Bananal e Santa Maria/Torto, DF. A área cinza representa o erro padrão da estimativa.

Figure 3. Species accumulation curve generated from permutations of individuals collected from streams of the Bananal and Santa Maria/Torto sub-basins, DF. Gray area represents the estimate standard error. 
Tabela 2. Lista das espécies, número de indivíduos (N) e constância de ocorrência (Const.) dos peixes coletados nos córregos das sub-bacias do Bananal e Santa Maria/Torto, DF.

Table 2. Species list, abundance (N), and occurrence constancy (Const.) of fishes collected at the streams of Bananal and Santa Maria/Torto sub-basins, DF.

\begin{tabular}{|c|c|c|}
\hline Táxon & $\mathbf{N}$ & Const. $(\%)$ \\
\hline \multicolumn{3}{|l|}{ Ordem Characiformes } \\
\hline \multicolumn{3}{|l|}{ CURIMATIDAE } \\
\hline Steindachnerina insculpta (Fernández-Yépez, 1948) & 1 & 1,8 \\
\hline \multicolumn{3}{|l|}{ CRENUCHIDAE } \\
\hline Characidium gomesi Travassos, 1956 & 3 & 3,6 \\
\hline Characidium sp. & 7 & 7,1 \\
\hline Characidium xanthopterum Silveira, Langeani, Graça, Pavanelli \& Buckup, 2008 & 6 & 3,6 \\
\hline Characidium zebra Eigenmann, 1909 & 6 & 5,4 \\
\hline \multicolumn{3}{|l|}{ CHARACIDAE } \\
\hline \multicolumn{3}{|l|}{ Subfamília Cheirodontinae } \\
\hline Kolpotocheirodon theloura Malabarba \& Weitzman, 2000 & 26 & 5,4 \\
\hline \multicolumn{3}{|l|}{ Subfamília Glandulocaudinae } \\
\hline Planaltina myersi Böhlke, 1954 & 326 & 16,1 \\
\hline \multicolumn{3}{|l|}{ Gêneros incertae sedis } \\
\hline Astyanax sp. & 965 & 76,8 \\
\hline Bryconamericus stramineus Eigenmann, 1908 & 1 & 1,8 \\
\hline Ctenobrycon sp. & 4 & 3,6 \\
\hline Hasemania sp. & 482 & 26,8 \\
\hline Hyphessobrycon balbus Myers, 1927 & 955 & 69,6 \\
\hline Knodus moenkhausii (Eigenmann \& Kennedy, 1903) & 5.558 & 23,2 \\
\hline Moenkhausia sp. & 48 & 7,1 \\
\hline \multicolumn{3}{|l|}{ Ordem Siluriformes } \\
\hline \multicolumn{3}{|l|}{ CALLYCHTYIDAE } \\
\hline Aspidoras fuscoguttatus Nijssen \& Isbrücker, 1976 & 17 & 8,9 \\
\hline \multicolumn{3}{|l|}{ LORICARIIDAE } \\
\hline \multicolumn{3}{|l|}{ Subfamília Neoplecostominae } \\
\hline Neoplecostomus corumba Zawadzki, Pavanelli \& Langeani, 2008 & 1 & 1,8 \\
\hline \multicolumn{3}{|l|}{ Subfamília Hypoptopomatinae } \\
\hline Microlepidogaster sp. & 36 & 25,0 \\
\hline \multicolumn{3}{|l|}{ Subfamília Hypostominae } \\
\hline Hypostomus ancistroides (Ihering, 1911) & 2 & 1,8 \\
\hline Hypostomus sp.1 & 2 & 3,6 \\
\hline Hypostomus sp. 2 & 41 & 10,7 \\
\hline Hypostomus sp.3 & 1 & 1,8 \\
\hline Hypostomus sp.4 & 3 & 1,8 \\
\hline \multicolumn{3}{|l|}{ HEPTAPTERIDAE } \\
\hline Heptapterus sp. & 18 & 12,5 \\
\hline Rhamdia quelen (Quoy \& Gaimard in Freycinet, 1824) & 6 & 5,6 \\
\hline \multicolumn{3}{|l|}{ Ordem Cyprinodontiformes } \\
\hline \multicolumn{3}{|l|}{ RIVULIDAE } \\
\hline Rivulus pictus Costa, 1989 & 67 & 12,5 \\
\hline \multicolumn{3}{|l|}{ POECILIIDAE } \\
\hline Phalloceros harpagos Lucinda, 2008 & 28 & 7,1 \\
\hline Poecilia reticulata Peters, $1859^{*}$ & 2 & 3,6 \\
\hline \multicolumn{3}{|l|}{ Ordem Perciformes } \\
\hline \multicolumn{3}{|l|}{ CHICLIDAE } \\
\hline Cichlasoma paranaense Kullander, 1983 & 2 & 1,8 \\
\hline
\end{tabular}

\footnotetext{
*Espécie exótica.
} 


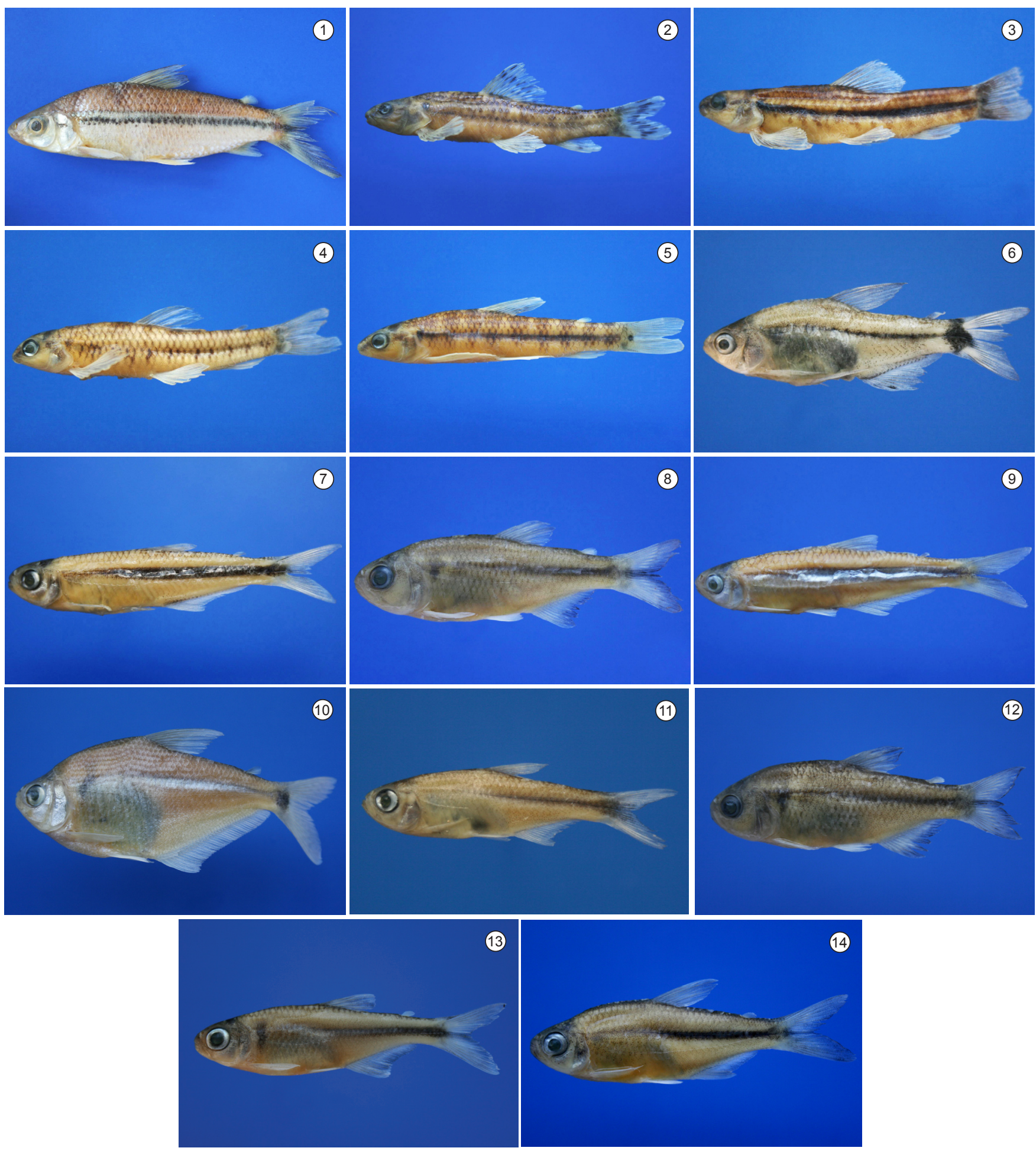

Figura 4. Exemplares representativos das espécies de peixes da ordem Characiformes coletadas nas sub-bacias do Bananal e Santa Maria/Torto, DF. O comprimento padrão do indivíduo fotografado é apresentado após o nome de cada espécie. 1) Steindachnerina insculpta, 91,49 mm;2) Characidium gomesi, 58,95 mm; 3) Characidium sp., 41,07 mm; 4) Characidium xamthopterum, 36,45 mm; 5) Characidium zebra, 46,64 mm; 6) Kolpotocheirodon theloura, 28,71 mm; 7) Planaltina myersi, 39,22 mm; 8) Astyanax sp., 37,44 mm; 9) Bryconamericus stramineus, 50,07 mm; 10) Ctenobrycon sp., 60,07 mm; 11) Hasemania sp., $21,07 \mathrm{~mm}$; 12) Hyphessobrycon balbus, 40,70 mm; 13) Knodus moenkhausii, 32,26 mm; e 14) Moenkhausia sp., 39,96 mm (Fotos de Pedro De Podestà).

Figure 4. Representative specimens of the Characiformes order, collected from the Bananal and Santa Maria/Torto sub-basins, DF. The standard length of the photographed individual is given following the species' name. 1) Steindachnerina insculpta, 91,49 mm; 2) Characidium gomesi, 58,95 mm; 3) Characidium sp., $41,07 \mathrm{~mm}$; 4) Characidium xamthopterum, $36,45 \mathrm{~mm}$; 5) Characidium zebra, 46,64 mm; 6) Kolpotocheirodon theloura, 28,71 mm; 7) Planaltina myersi, $39,22 \mathrm{~mm}$; 8) Astyanax sp., 37,44 mm; 9) Bryconamericus stramineus, 50,07 mm; 10) Ctenobrycon sp., 60,07 mm; 11) Hasemania sp., 21,07 mm; 12 ) Hyphessobrycon balbus, 40,70 mm; 13) Knodus moenkhausii, 32,26 mm; e 14) Moenkhausia sp., 39,96 mm (Pictures by Pedro De Podestà). 

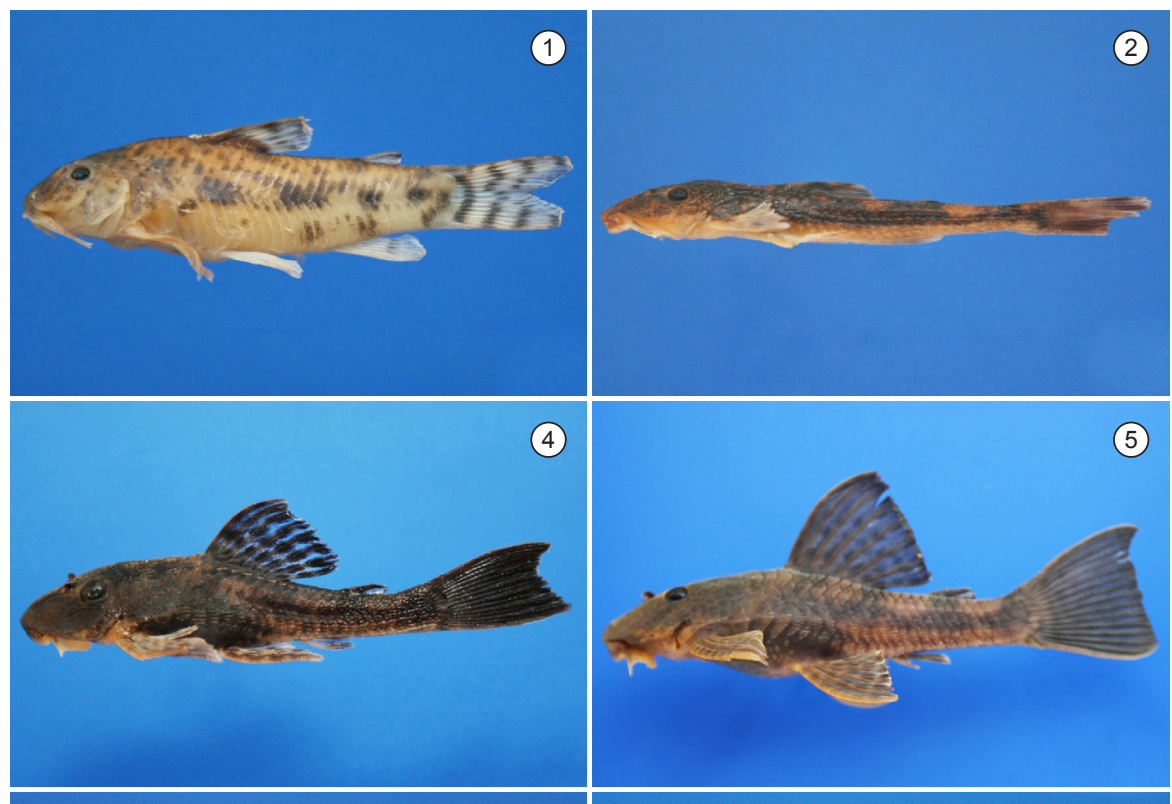

(7)

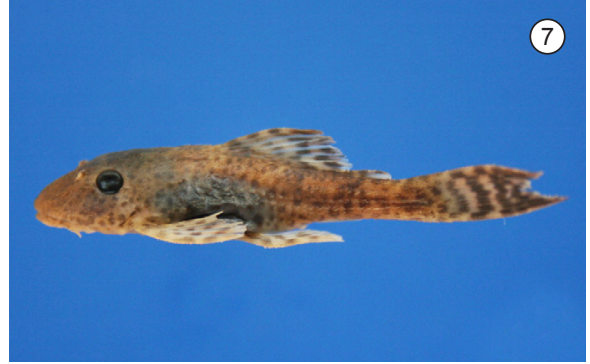

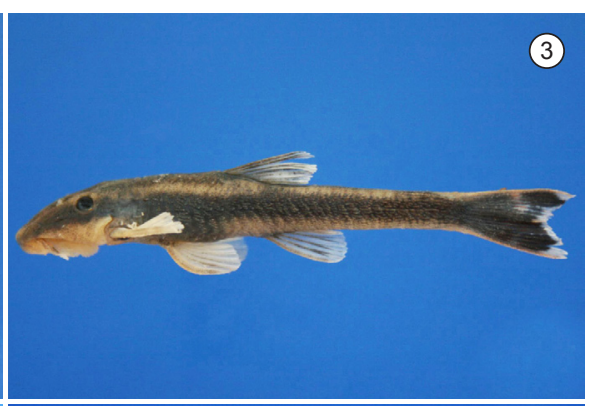

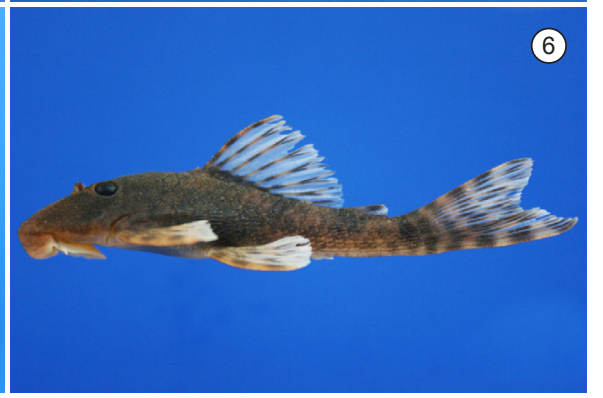

(8)

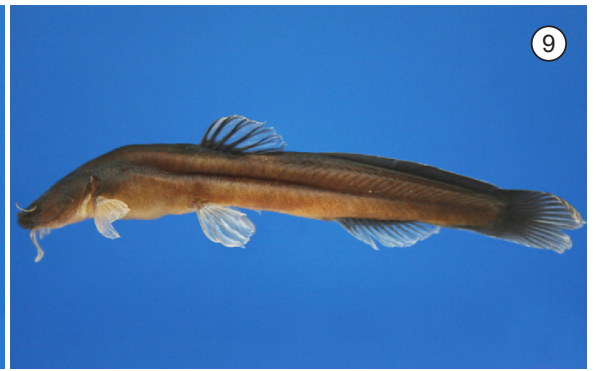

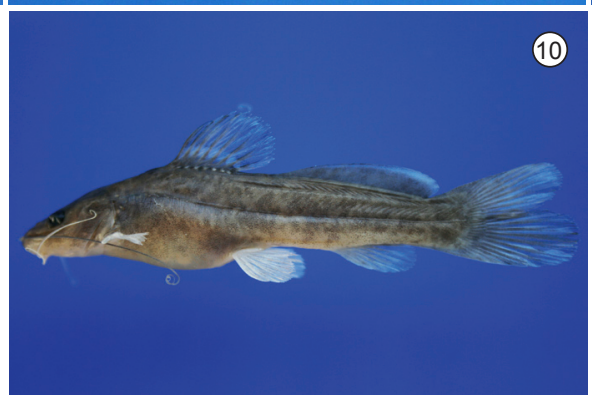

Figura 5. Exemplares representativos das espécies de peixes da ordem Siluriformes coletadas nas sub-bacias do Bananal e Santa Maria/Torto, DF. O comprimento padrão do indivíduo fotografado é apresentado após o nome de cada espécie. 1) Aspidoras fuscoguttatus, 27,70 mm; 2) Neoplecostomus corumba, 28,62 mm; 3) Microlepidogaster sp., 34,98 mm; 4) Hypostomus ancistroides, 31,46 mm; 5) Hypostomus sp.1, 65,80 mm; 6) Hypostomus sp.2, 42,37 mm; 7) Hypostomus sp.3, 26,96 mm; 8) Hypostomus sp.4, 22,06 mm; 9) Heptapterus sp., 56,18 mm; e 10) Rhamdia quelen, 61,69 mm (Fotos de Pedro De Podestà).

Figure 5. Representative specimens of the Siluriformes order, collected from the Bananal and Santa Maria/Torto sub-basins, DF. The standard length of the photographed individual is given following the species' name. 1) Aspidoras fuscoguttatus, 27,70 mm; 2) Neoplecostomus corumba, 28,62 mm; 3 ) Microlepidogaster sp., $34,98 \mathrm{~mm}$; 4) Hypostomus ancistroides, 31,46 mm; 5) Hypostomus sp.1, 65,80 mm; 6) Hypostomus sp.2, 42,37 mm; 7) Hypostomus sp.3, 26,96 mm; 8) Hypostomus sp.4, 22,06 mm; 9) Heptapterus sp., 56,18 mm; e 10) Rhamdia quelen, 61,69 mm (Pictures by Pedro De Podestà).

(64,5\%), Astyanax sp. (11,2\%), Hyphessobrycon balbus $(11,1 \%)$, Hasemania sp. (5,6\%) e Planaltina myersi (3,8\%). As espécies mais comuns, consideradas constantes, foram Astyanax sp. e H. balbus (Tabela 2). Hasemania sp. e Microlepidogaster sp., com constâncias de ocorrência iguais a 26,8\% e 25,0\%, respectivamente, foram espécies acessórias. As demais espécies possuem ocorrência acidental.

Onze espécies $(39,3 \%)$ são novas para ciência; entre elas, Heptapterus sp. e Ctenobrycon sp. são registradas pela primeira vez no presente estudo. Vale ressaltar que o registro do gênero Ctenobrycon é inédito para a bacia do Alto Rio Paraná. Nenhuma das espécies coletadas encontra-se ameaçada de extinção (Rosa \& Lima 2005, 2008). Das 28 espécies, apenas uma é exótica (Poecilia reticulata), nativa da América Central e norte da América do Sul (FISHBASE 2009), e foi representada por dois indivíduos (machos) nas unidades amostrais 7 e 14 .

A riqueza variou de 1 a 10 espécies entre os trechos e estações amostradas, enquanto a abundância variou entre 1 e 1.743 indivíduos (Tabela 3). As unidades amostrais 7 e 14 apresentaram os maiores valores de riqueza e abundância ao longo das estações (Tabela 3). Quanto ao índice de Simpson, a unidade amostral 6, nas estações 

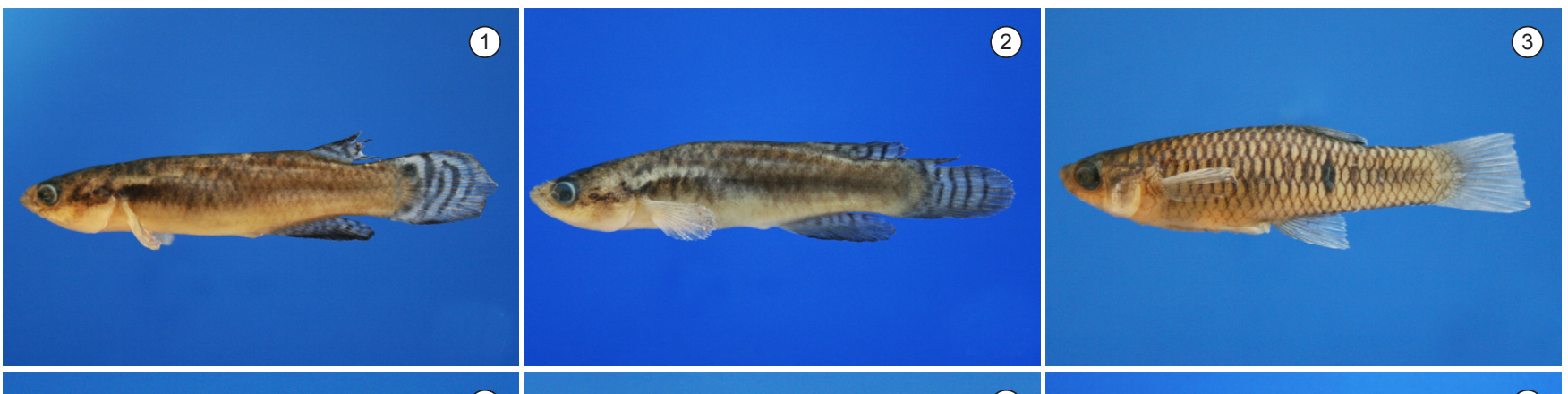

(4)
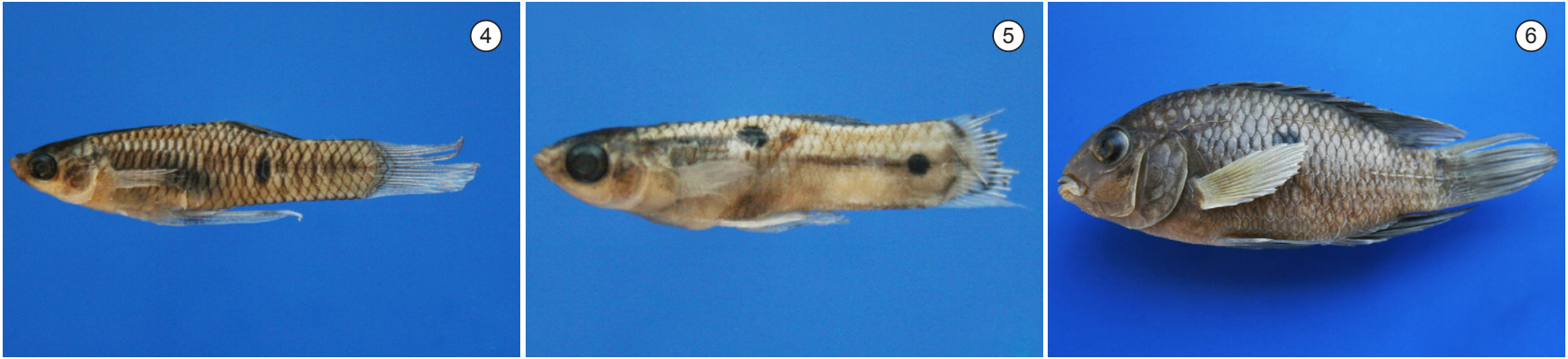

Figura 6. Exemplares representativos das espécies de peixes da ordem Cyprinodontiformes e Perciformes coletadas nas sub-bacias do Bananal e Santa Maria/ Torto, DF. O comprimento padrão do indivíduo fotografado é apresentado após o nome de cada espécie. 1) Rivulus pictus (fêmea), 29,96 mm; 2) R. pictus (macho), 31,98 mm;3) Phalloceros harpagos (fêmea), 28,70 mm; 4) P. harpagos (macho), 25,70 mm; 5) Poecilia reticulata (macho), 17,87 mm; e 6) Cichlasoma paranaense, 70,96 mm (Fotos de Pedro De Podestà).

Figure 6. Representative specimens of the Perciformes and Cyprinodontiformes orders, collected from the Bananal and Santa Maria/Torto sub-basins, DF. The standard length of the photographed individual is given following the species' name. Orders Perciformes and Cyprinodontiformes representative fishes collected in Bananal and Santa Maria/Torto sub-basins, DF. The standard length of the photographed individual is given after the name of each species. 1) Rivulus pictus (fêmea), 29,96 mm; 2) R. pictus (macho), 31,98 mm; 3) Phalloceros harpagos (fêmea), 28,70 mm; 4) P. harpagos (macho), 25,70 mm; 5) Poecilia reticulata (macho), 17,87 mm; e 6) Cichlasoma paranaense, 70,96 mm (Pictures by Pedro De Podestà).

Tabela 3. Riqueza de espécies, abundância e índice de Simpson $(l)$ ao longo das estações $(\mathrm{SC}=$ transição seca para chuva, $\mathrm{C}=$ chuva, $\mathrm{CS}=$ transição chuva para seca e $\mathrm{S}=$ seca) nas unidades amostrais dos córregos das sub-bacias do Bananal e Santa Maria/Torto, DF.

Table 3. Species richness, abundance, and Simpson diversity index $(l)$ throughout the seasons $(\mathrm{SC}=$ dry/rainy transition, $\mathrm{C}=\mathrm{rainy}, \mathrm{CS}=$ rainy/dry transition and $\mathrm{S}=$ dry) in stretches sampled at the Bananal and Santa Maria/Torto sub-basins, DF.

\begin{tabular}{|c|c|c|c|c|c|c|c|c|c|c|c|c|}
\hline \multirow[t]{2}{*}{ Trecho } & \multicolumn{4}{|c|}{ Riqueza de espécies } & \multicolumn{4}{|c|}{ Abundância } & \multicolumn{4}{|c|}{$l$} \\
\hline & $\mathrm{SC}$ & $\mathbf{C}$ & CS & $\mathbf{S}$ & SC & $\mathbf{C}$ & CS & $\mathbf{S}$ & SC & $\mathbf{C}$ & CS & $\mathbf{S}$ \\
\hline 1 & 2 & 2 & 1 & 1 & 24 & 16 & 19 & 6 & 0,28 & 0,22 & 0,00 & 0,00 \\
\hline 2 & 3 & 1 & 4 & 1 & 180 & 34 & 27 & 67 & 0,14 & 0,00 & 0,62 & 0,00 \\
\hline 3 & 2 & 2 & 2 & 2 & 122 & 44 & 81 & 54 & 0,16 & 0,04 & 0,33 & 0,10 \\
\hline 4 & 2 & 2 & 2 & 2 & 45 & 31 & 87 & 87 & 0,04 & 0,27 & 0,44 & 0,24 \\
\hline 5 & 3 & 4 & 3 & 3 & 60 & 46 & 71 & 82 & 0,42 & 0,33 & 0,50 & 0,43 \\
\hline 6 & 4 & 5 & 7 & 7 & 13 & 90 & 157 & 94 & 0,69 & 0,20 & 0,49 & 0,73 \\
\hline 7 & 10 & 7 & 10 & 9 & 383 & 350 & 930 & 397 & 0,49 & 0,65 & 0,48 & 0,33 \\
\hline 8 & 6 & 3 & 3 & 4 & 17 & 95 & 27 & 25 & 0,61 & 0,24 & 0,14 & 0,28 \\
\hline 9 & 1 & 2 & 5 & 3 & 1 & 18 & 35 & 25 & 0,00 & 0,10 & 0,50 & 0,38 \\
\hline 10 & 2 & 1 & 1 & 4 & 8 & 2 & 3 & 33 & 0,50 & 0,00 & 0,00 & 0,62 \\
\hline 11 & 2 & 1 & 2 & 1 & 27 & 7 & 18 & 4 & 0,48 & 0,00 & 0,50 & 0,00 \\
\hline 12 & 1 & 2 & 1 & 2 & 12 & 10 & 9 & 5 & 0,00 & 0,18 & 0,00 & 0,32 \\
\hline 13 & 5 & 3 & 4 & 6 & 113 & 90 & 36 & 29 & 0,41 & 0,22 & 0,54 & 0,66 \\
\hline 14 & 8 & 9 & 4 & 7 & 826 & 1045 & 1743 & 754 & 0,11 & 0,32 & 0,06 & 0,25 \\
\hline Total & 22 & 15 & 16 & 20 & 1831 & 1878 & 3243 & 1662 & - & - & - & - \\
\hline
\end{tabular}


seca e transição da seca para chuva, apresentou os maiores valores, seguida pela unidade amostral 13 na estação seca e unidade amostral 7 na estação chuvosa (Tabela 3 ).

\section{Discussão}

Apesar de ainda crescente, nota-se uma tendência à estabilização da curva de acumulação, indicando alto grau de eficiência das amostragens. A riqueza estimada para os cursos d'água das sub-bacias do Bananal e Santa Maria/Torto apresentou-se de acordo com o proposto por Matthews (1998), para riachos tropicais com pequenas dimensões, reforçando a adequação metodológica às dimensões dos riachos amostrados. É importante ressaltar que, por constantes extinções e invasões locais, amostragens contínuas de longo prazo podem vir a adicionar indefinidamente novas espécies as já existentes (Gotelli \& Colwell 2001).

A alta riqueza das ordens Characiformes e Siluriformes, para os córregos das sub-bacias do Bananal e Santa Maria/Torto, apresenta-se de acordo com o encontrado para os riachos não estuarinos da região Neotropical (Lowe-McConnell 1999, Castro 1999). A maioria das espécies coletadas pertence às famílias Characidae e Loricariidae, refletindo o padrão encontrado nas águas continentais brasileiras (Reis et al. 2003, Buckup et al. 2007). O pequeno porte dos riachos, com cursos irregulares e instáveis (flutuações ambientais), favorece a ocorrência dessas espécies caracterizadas pela plasticidade e resistência às variações abióticas. Um exemplo que merece destaque é Knodus moenkhausii, que foi a espécie de maior abundância, contribuindo com mais da metade do número de indivíduos coletados. Em estudos recentes, essa dominância vem sendo continuamente observada em riachos da bacia do Alto Paraná (Castro et al. 2005, Casatti et al. 2006) e é explicada pelo oportunismo alimentar, que lhe garante permanentes fontes de energia, a qual boa parte é alocada para reprodução, permitindo a ocorrência dessa espécie até mesmo em ambientes impactados (Ceneviva-Bastos \& Casatti 2007).

A maioria das espécies ocorreu em poucas amostragens, sendo encontradas restritamente em alguns trechos ou estações. Algumas espécies por possuírem pequenos portes não realizam grandes deslocamentos, o qual pode estar restringindo suas distribuições a micro-hábitats específicos, tornando as populações isoladas e favorecendo a especiação alopátrica (Castro 1999). Os barramentos naturais formados por trechos encachoeirados e por troncos de árvores caídos também dificultam os deslocamentos dessas espécies (Apone et al. 2008). Pringle et al. (1988) sugerem que comunidades biológicas em ambientes lóticos podem responder a variações características de manchas do ambientes (i.e. mosaicos) ao longo das bacias de drenagem.

Apesar de possuírem maior abundância nas regiões de cabeceira, Astyanax sp. e Hyphessobrycon balbus tiveram ampla distribuição ao longo das estações do ano e das localidades de coleta. Essas espécies, por atingirem maior porte, conseguem realizar maiores deslocamentos, ultrapassando obstáculos, estando presentes nos diversos trechos da bacia. A plasticidade alimentar dessas espécies permite também que elas explorem tanto alimentos de origem animal quanto vegetal nos diversos ambientes dos córregos (Schneider 2008).

As novas espécies amostradas e as novas ocorrências registradas demonstram a carência de estudos para a região e reforçam a peculiaridade (endemismo) das regiões de cabeceira. As espécies Heptapterus sp. e Ctenobrycon sp. tiveram seus primeiros registros no presente trabalho, cabendo lembrar que suas ocorrências podem vir a ser ampliadas com o advento de novos estudos. No entanto, é interessante ressaltar a relevância do Parque Nacional de Brasília com suas restrições de uso, o qual viabiliza a conservação de espécies nativas e processos naturais do bioma Cerrado (IBAMA \&
FUNATURA 1998). Este fato reforça a necessidade de manutenção e correto manejo desses específicos ecossistemas.

A ocorrência da família Poeciliidae é um dos principais indicadores de qualidade em riachos, visto sua tolerância às variações nos diversos tipos de hábitats, muitos deles impactados (Kennard et al. 2005). De acordo com Casatti et al. (2006), a ocorrência de algumas espécies exóticas possui forte correlação com descritores de hábitats degradados. Nos trechos amostrados, foi encontrada uma espécie exótica (Poecilia reticulata) pertencente à família Poeciliidae; no entanto, apenas dois indivíduos machos foram coletados. A Unidade de Conservação pode estar mantendo as características naturais dos ambientes (IBAMA \& FUNATURA 1998) impedindo o estabelecimento da espécie alienígena. A espécie nativa Phalloceros harpagos, também pertencente à família Poecilidae, apresentou maiores abundâncias nos mesmos pontos onde $P$. reticulata foi encontrada. Novos estudos sistematizados podem evidenciar possíveis interações biológicas (p.ex., exclusões competitivas) entre essas duas espécies.

Alguns estudos em riachos de cabeceira na bacia do Alto Paraná mostram uma riqueza variando entre três e 26 espécies em unidades amostrais com $100 \mathrm{~m}$ de extensão (Castro et al. 2003, 2004). As dimensões das unidades amostrais, a posição longitudinal do ponto de coleta no curso d'água e os padrões regionais e biogeográficos de diversidade podem influenciar a riqueza local de espécies (Matthews 1998). Viana (1989), caracterizando a estruturação da taxocenose íctica no Ribeirão Santana (bacia do Alto Rio Paraná, sul do Distrito Federal), verificou que em resposta ao aumento da estabilidade e complexidade do ambiente, ao longo do gradiente longitudinal, há um aumento na diversidade de espécies, biomassa e guildas tróficas. Os maiores valores de riqueza e abundância encontrados nos trechos a jusante (trechos 7, 13 e 14), seja pela adição ou substituição de espécies, pode ser explicado pela maior complexidade e volume de hábitats (Angermeier \& Schlosser 1989, Schlosser 1990) e, ainda, pelo aumento na produtividade do ecossistema (Vannote et al. 1980) evidenciado ao longo do gradiente longitudinal dos cursos d'água. Muito embora, padrões estocásticos na estruturação hierárquica ao longo das ordens de drenagem podem ser verificados em função da distribuição das espécies consideradas raras (Ribeiro et al. 2008).

O entendimento da composição e distribuição das comunidades aquáticas em ambientes íntegros é premente visto a acelerada degradação ambiental observada em diversos ecossistemas límnicos em todo mundo (Duncan \& Lockwood 2001). As atividades humanas surgem como uma nova contribuição para os processos de estruturação das comunidades biológicas (Hooper et al. 2005). Devido à carência de estudos ecológicos utilizando a taxocenose íctica em ecossistemas aquáticos lóticos preservados de cabeceira, os resultados obtidos mostram-se bastante valiosos e servem como referência para a região. Essas informações podem contribuir para o manejo e monitoramento de pequenas bacias em Unidades de Conservação e, ainda, subsidiar a implementação de políticas públicas para a conservação de nascentes e pequenos mananciais.

\section{Agradecimentos}

Somos gratos ao Dr. Francisco Langeani, pelo auxílio nas identificações dos peixes; ao Santos Balbino pelo auxílio nas campanhas de campo; ao Ricardo Pavan, José Braz, Thiago Couto, Bernardo Buta, Filipe Fortes, Juliana Fonseca, Carlos de Melo, Guthenberg Falcon, Paula Jota e Flávio Cardoso pelo auxílio nas coletas dos peixes; à Marcela A. Brasil e Rafael Maia pelas sugestões e revisão dos textos em inglês; aos revisores anônimos pelas valiosas sugestões para versão final do manuscrito; ao Programa de Pós-Graduação em Ecologia da Universidade de Brasília pelo suporte e auxílio financeiro; ao Conselho Nacional de Desenvolvimento Científico 
e Tecnológico (CNPq), pelo fornecimento da bolsa de mestrado a PPUA e a MS; ao Parque Nacional de Brasília, pelo apoio logístico e ao Instituto Brasileiro do Meio Ambiente (IBAMA), pelo fornecimento da licença de coleta (Processo $n^{\circ}$ 02001,003286/06-02 e licença $\left.n^{\circ} 188 / 2006\right)$.

\section{Referências Bibliográficas}

AGOSTINHO, A.A., GOMES, L.C., SUZUKI, H.I. \& JÚLIO Jr., H.F. 2004. Migratory fishes of the upper Paraná river basin. In Migratory fishes of South America: biology, fisheries and conservation status (J. Carolsfeld, B. Harvey, C. Ross \& A. Baer, eds.). World Fisheries Trust, World Bank, IDRC.

AGOSTINHO, A.A., THOMAZ, S.M. \& GOMES, L.C. 2005. Conservação da biodiversidade em águas continentais do Brasil. Megadiversidade, 1(1):70-78.

ANGERMEIER, P.L. \& SCHLOSSER, I.J. 1989. Species area relationship for stream fish. Ecology, 70(5):1450-1462.

APONE, F., OLIVEIRA, A.K. \& GARAVELLO, L.C. 2008. Composição da ictiofauna do rio Quilombo, tributário do rio Mogi-Guaçu, bacia do alto rio Paraná, sudeste do Brasil. Biota Neotrop. 8(1): http://www. biotaneotropica.org.br/v8n1/pt/abstract?article+bn02208012008 (último acesso em 05/11/2008).

ARAÚJO, N.B. \& TEJERINA-GARRO, F.L. 2007. Composição e diversidade da ictiofauna em riachos do Cerrado, bacia do ribeirão Ouvidor, alto rio Paraná, Goiás, Brasil. Rev. Braz. Zool. 24(4):981-990.

BENEDITO-CECILIO, E., MINTE-VERA, C.V., ZAWADZKI, C.H., PAVANELLI, C.S., RODRIGUES, F.H.G. \& GIMENES, M.F. 2004. Ichthyofauna from the Emas National Park region: composition and structure. Braz. J. Biol. 64(3A):371-382.

BUCKUP, P.A., MENEZES, N.A. \& GHAZZI, M.S. 2007. Catálogo das espécies de peixes de água doce do Brasil. Editora do Museu Nacional, Rio de Janeiro.

CASATTI, L., LANGEANI, F. \& CASTRO, R.M.C. 2001. Peixes de riacho do Parque Estadual do Morro do Diabo, bacia do Alto Rio Paraná. Biota Neotrop. 1(1-2): http://www.biotaneotropica.cria.org.br/v1n12/pt/ fullpaper?bn00201122001+pt (último acesso em 03/11/2008).

CASATTI, L., LANGEANI, F., SILVA, A.M. \& CASTRO, R.M.C. 2006. Stream fish, water and habitat quality in a pasture dominated basin, southeastern Brazil. Braz. J. Biol. 66(2B):681-696.

CASTRO, R.M.C. 1999. Evolução da ictiofauna de riachos sul-americanos: padrões gerais e possíveis processos causais. In Ecologia de peixes de riachos (E.P. Caramaschi, R. Mazzoni \& P.R. Peres-Neto, eds.). PPGEUFRJ, Rio de Janeiro, p. 139-155.

CASTRO, R.M.C., CASATTI, L., SANTOS, H.F., FERREIRA, K.M., RIBEIRO, A.C., BENINE, R.C., DARDIS, G.Z.P., MELO, A.L.A., STOPLIGLIA, R., ABREU, T.X., BOCKMANN, F.A., CARVALHO, M., GIBRAN, F.Z. \& LIMA, F.C.T. 2003. Estrutura e composição da ictiofauna de riachos do Rio Paranapanema, Sudeste e Sul do Brasil. Biota Neotrop. 3(1): http://www.biotaneotropica.org.br/v3n1/pt/ abstract?article+BN01703012003 (último acesso em 23/04/2008).

CASTRO, R.M.C., CASATTI, L., SANTOS, H.F., MELO, A.L.A., MARTINS, L.S.F., FERREIRA, K.M., GIBRAN, F.Z., BENINE, R.C., CARVALHO, M., RIBEIRO, A.C., ABREU, T.X., BOCKMANN, F.A., PELIÇÃO, G.Z., STOPLIGLIA, R. \& LANGEANI, F. 2004. Estrutura e composição da ictiofauna de riachos da bacia do Rio Grande no estado de São Paulo, sudeste do Brasil. Biota Neotrop. 4(1): http://www.biotaneotropica.cria. org.br/v4n1/pt/download?article+BN01704012004 (último acesso em 23/04/2008).

CASTRO, R.M.C., CASATTI, L., SANTOS, H.F., VARI, R.P., MELO, A.L.A., MARTINS, L.S.F., ABREU, T.X., BENINE, R.C., GIBRAN, F.Z., RIBEIRO, A.C., BOCKMANN, F.A., CARVALHO, M., PELIÇÃO, G.Z.P., FERREIRA, K.M., STOPLIGLIA, R. \& AKAMA, A. 2005. Structure and composition of the stream ichthyofauna of four tributary rivers of the upper Rio Paraná basin, Brazil. Ichthyol. Explor. Freshwaters, 16(3):193-214.
CENEVIVA-BASTOS, M. \& CASATTI, L. 2007. Oportunismo alimentar de Knodus moenkhausii (Teleostei: Characidae): uma espécie abundante em riachos do noroeste do Estado de São Paulo, Brasil. Iheringia, Sér. Zool. 97(1):7-15.

CHAO, A. 1987. Estimating the population size for capture-recapture data with unequal catchability. Biometrics, 43(4):783-791.

DAJOZ, R. 1978. Ecologia Geral. Editora Vozes, Rio de Janeiro.

DUNCAN, J.R. \& LOCKWOOD, J.L. 2001. Extinction in a field of bullets: a search for causes in the decline of world's freshwater fishes. Biol. Conser. 102(1):97-105.

FIALHO, A.P., OLIVEIRA, L.G., TEJERINA-GARRO, F.L. \& GOMES, L.C. 2007. Fish assemblages structure in tributaries of the meia Ponte River, Goiás, Brasil. Neotrop. Ichthyol. 5(1):53-60.

FISHBASE. A Global Information System on Fishes. Available from: <http:// www.fishbase.org/home.htm>. (último acesso em 25/02/2009).

GORMAN, O.T. \& KARR, J.R. 1978. Habitat structure and stream fish communities. Ecology, 59(3):507-515.

GOTELLI, N.J. \& COLWELL, R.K. 2001. Quantifying biodiversity: procedures and pitfalls in the measurement and comparison of species richness. Ecol. Lett. 4(4):379-391.

HOOPER, D.U., CHAPIN III, F.S., EWEL, J.J., HECTOR, A., INCHAUSTI, P., LAVOREL, S., LAWTON, J.H., LODGE, D.M., LOREAU, M., NAEEM, S., SCHMID, B., SETÄLÄ, H., SYMSTAD, A.J., VANDERMEER, J. \& WARDLE, D.A. 2005. Effects of biodiversity on ecosystem functioning: a consensus of current knowledge. Ecol. Monogr. 75(1):3-35.

HORTON, R.E. 1945. Erosional development of streams and their drainage basins, hydrophysical approach to quantitative morphology. Geol. Soc. Am. Bull. 56(3):275-370.

IBAMA \& FUNATURA. 1998. Plano de Manejo do Parque Nacional de Brasília. Brasília. (Revisão).

JACKSON, D.A., PERES-NETO, P.R. \& OLDEN, J.D. 2001. What controls who is where in freshwater fish communities: the role of biotic, abiotic, and spatial factors. Can. J. Fish. Aquat. Sci. 58(1):157-170.

KARR, J.R. 1981. Assessment of biotic integrity using fish communities. Fisheries, 6(6):21-27.

KENNARD, M.J.; ARTHINGTON, A.H.; PUSEY, B.J. \& HARCH, B.D. 2005. Are alien fish reliable indicator of river health? Freshwater Biol. 50(1):174-193.

LANGEANI, F., CASTRO, R.M.C., OYAKAWA, O.T., SHIBATTA, O.A., PAVANELLI, C.S. \& CASATTI, L. 2007. Diversidade da ictiofauna do Alto Rio Paraná: composição atual e perspectivas futuras. Biota Neotrop. 7(3): http://www.biotaneotropica.org.br/v7n3/pt/ abstract?article+bn03407032007 (último acesso em 23/04/2008).

LEE, S.M. \& CHAO, A. 1994. Estimating population size via sample coverage for closed capture-recapture models. Biometrics, 50(1):88-97.

LOWE-McCONNELL, R.H. 1999. Estudos ecológicos em comunidades de peixes tropicais. EDUSP, São Paulo.

MAGURRAN, A.E. 1988. Ecological diversity and its measurements. Cambridge University Press, London.

MATTHEWS, W.J. 1998. Patterns in freshwater fish ecology. Chapman \& Hall, Norwell, Massachusetts.

Ministério do Meio Ambiente \& The Nature Conservancy - MMA/TNC. 2007. Unidades de Conservação e Terras Indígenas dos Biomas Cerrado e Pantanal. Brasília.

MOUILLOT, D. \& LEPRÊTRE, A. 1999. A comparison of species diversity estimators. Res. Popul. Ecol. 41:203-215.

OKSANEN, J., KINDT, R., LEGENDRE, P., O'HARA, B. \& STEVENS, M.H.H. 2007. Vegan: Community Ecology Package. [s.n.], [S.L.]. R package version 1.8-8.

Organização das Nações Unidas para a Educação, a Ciência e a Cultura - UNESCO. 2001. Vegetação do Distrito Federal: Tempo e Espaço. UNESCO Brasil, Brasília. 
PERES-NETO, P.R. 2004. Patterns in the co-occurrence of fish species in streams: the role of site suitability, morphology and phylogeny versus species interactions. Oecologia, 140:352-360.

PINTO, M.N. 1993. Caracterização geomorfológica do Distrito Federal. In Cerrado: caracterização, ocupação e perspectiva (M.N. Pinto, coord.). Editora Universidade de Brasília, Brasília.

POFF, N.L. 1997. Landscape filters and species traits: towards mechanistic understanding and prediction in stream ecology. J. N. Am. Benthol. Soc. 16(2):391-409

PRINGLE, C.M., NAIMAN, R.J., BRETSCHKO, G., KARR, J.R., OSWOOD, M.W., WEBSTER, J.R., WELCOMME, R.L. \& WINTERBOURN, M.J. 1988. Patch dynamics in lotic systems: the stream as a mosaic. J. N. Am. Benthol. Soc. 7(4):503-524.

R DEVELOPMENT CORE TEAM. 2007. R: A language and environment for statistical computing. R Foundation for Statistical Computing, Vienna, Austria.

REIS, R.E., KULLANDER, S.O. \& FERRARIS, C. 2003. Check list of the freshwater fishes of South and Central America (CLOFFSCA). EDIPUCRS, Porto Alegre.

RIBEIRO, M.C.L.B., PERDIGÃO, V.S.J. \& RAMOS, H.A.C. 2008 Ictiofauna. In Águas Emendadas (F.O. Fonseca, org.). Seduma, Brasília, p. 253-272.

ROSA, R.S. \& LIMA, F.C.T. 2005. Peixes. In Lista da fauna ameaçada de extinção: incluindo as espécies quase ameaçadas e deficientes em dados (A.B.M. Machado, C.S. Martins \& G.M. Drummond, eds.). Fundação Biodiversitas, Belo Horizonte, p. 65-81.

ROSA, R.S. \& LIMA, F.C.T. 2008. Peixes. In Livro vermelho da fauna brasileira ameaçada de extinção (A.B.M. Machado, G.M. Drummond
\& A.P. Paglia, eds.). Ministério do Meio Ambiente, Brasília; Fundação Biodiversitas, Belo Horizonte, p. 8-285.

SCHLOSSER, I.J. 1990. Environmental variation, life history attributes, and community structure in stream fish: implications for environmental management and assessment. Environ. Manage. 14:621-628.

SCHNEIDER, M. Composição e estrutura trófica da comunidade de peixes de riachos da sub-bacia do ribeirão Bananal, Parque Nacional de Brasília, bioma Cerrado, DF. Dissertação de Mestrado, Universidade de Brasília, Brasília.

STRAHLER, A.N. 1957. Quantitative analysis of watershed geomorphology. Trans. Am. Geophys. Union. 38:913-920.

UIEDA, V.S. \& CASTRO, R.M.C. 1999. Coleta e fixação de peixes de riacho. In Ecologia de peixes de riachos (E.P. Caramaschi, R. Mazzoni \& P.R. Peres-Neto, eds.). PPGE-UFRJ, Rio de Janeiro, p. 1-22.

VANNOTE, R.L., MINSHALL, G.W., CUMMINS, K.W., SEDELL, J.R \& CUSHING, C. E. 1980. The river continuum concept. Can. J. Fish. Aquat. Sci. 37:130-137.

VARI, R. P. \& MALABARBA, L. R. 1998. Neotropical ichthyology: an overview. In Phylogeny and classification of neotropical fishes (L.R. Malabarba, R.E. Reis, R.P. Vari \& Z.M.S. Lucena, eds.). Edipucrs, Porto Alegre, p. 1-11.

VIANA, J.P. 1989. Estrutura da comunidade dos peixes do Ribeirão Sant'ana (Brasília - DF) ao longo de gradientes ambientais. Dissertação de Mestrado, Universidade de Brasília, Brasília.

Recebido em 03/05/08

Versão reformulada recebida em 12/11/08

Publicado em 16/03/09 


\section{Appendix}

Material testemunho das 28 espécies de peixes coletadas nos córregos das sub-bacias do Bananal e Santa Maria/Torto, DF, tombados na Coleção Ictiológica da Universidade de Brasília (CIUnB) e na Coleção de Peixes do Departamento de Zoologia e Botânica da Universidade Estadual Paulista, São José do Rio Preto (DZSJRP)

Aspidoras fuscoguttatus CIUnB 14, 16, 173, 180, 220, DZSJRP 10.813; Astyanax sp. CIUnB 1-3, 6, 7, 12, 25, 33-36, 39, 40, 42, 43, 46, 50-52, 54, 55, 59, 60, 63, 71, 72, 74-76, 78-80, 82, 85, 90, 161, 162, 165-168, 178, 183, 194, 196-199, 202, 204, 208-212, 218, 228, 243, 245, 254, 312, 318, DZSJRP 10.817, 10.819, 10.0824; Bryconamericus stramineus CIUnB 61; Characidium gomesi CIUnB 15, 246; Characidium sp. CIUnB 29, 89, 193, 234, DZSJRP 10.822; Characidium xamthopterum CIUnB 13, 221, DZSJRP 10.812; Characidium zebra CIUnB 38, 81, 247, DZSJRP 10.821; Cichlasoma paranaense CIUnB 87; Ctenobrycon sp. CIUnB 64, 84, 86, DZSJRP 10.833; Hasemania sp. CIUnB 22, 41, 67, 91, 93, 94, 174, 185, 200, 205, 219, 223, 248, 255, 320, DZSJRP 10.801, 10.807, 10.829; Hyphessobrycon balbus CIUnB 5, 9, 23, 30, 53, 58, 65, 170, 190, 215, 231, 235, 239, 242, 309-311, 313-317, 319, 321-337, DZSJRP 10.818, 10.825; Hypostomus ancistroides CIUnB 257; Hypostomus sp.1 CIUnB 28, 164; Hypostomus sp. 2 CIUnB 32, 47, 201, 230, 241, 249, DZSJRP 10.809, 10.816; Hypostomus sp.3 CIUnB 48; Hypostomus sp.4 CIUnB 207; Heptapterus sp. CIUnB 11, 57, 171, 213, 232, 238, 244, DZSJRP 10.803, 10.804, 10.815; Knodus moenkhausii CIUnB 4, 20, 45, 62, 68, 92, 163, 177, 186, 187, 203, 216, 222, 256; Kolpotocheirodon theloura CIUnB 18, 179, 226, DZSJRP 10.831; Microlepidogaster sp. CIUnB 27, 31, 37, 70, 73, 77, 181, 189, 191, 195, 229, 233, 237, 240, DZSJRP 10.823, 10.827; Moenkhausia sp. CIUnB 21, 66, 188, 225, DZSJRP 10.799, 10.800, 10.805; Neoplecostomus corumba CIUnB 250; Phalloceros harpagos CIUnB 24, 182, 227, 252, DZSJRP 10.826; Planaltina myersi CIUnB 19, 49, 69, 88, 175, 184, 206, 224, 253, DZSJRP 10.802, 10.832; Poecilia reticulata CIUnB 17, 251; Rhamdia quelen CIUnB 8, 44, 172, 217, DZSJRP 10.798; Rivulus pictus CIUnB 10, 26, 56, 169, 192, 214, 236, DZSJRP 10.814; Steindachnerina insculpta CIUnB 83. 